\title{
El gusto en los cuerpos veracruzanos: retóricas y prácticas culinarias y sexuales ${ }^{1}$
}

\section{The Taste in Veracruzan Bodies: Culinary and Sexual Rhetorics and Practices}

\author{
Juan Antonio Flores Martos \\ Universidad de Castilla-La Mancha
}

Centro Est. Univ. Talavera de la Reina

\section{RESUMEN}

Esta contribución se enmarca en la teoría y corriente de la antropología de los sentidos, y en particular, intenta explorar el sentido del gusto — el gusto sensual - en la cultura urbana de Veracruz, México. El artículo es un estudio etnográfico sobre el lugar que las retóricas y prácticas referidas a comidas y al sexo tienen en la sociedad e imaginación social veracruzana, a partir de mi trabajo de campo realizado en los años 90 en esta ciudad. Historias y discursos diferentes son analizados en una aproximación para comprender la "gustación del mundo" hegemónica y singular entre las gentes de Veracruz. Centro mi análisis en los campos de la sociabilidad, la gastronomía y la sexualidad que comprometen los sentidos en la vida cotidiana veracruzana. De modo especial, estudio lo sensorial como retórica identitaria, los platos veracruzanos como mapamundis culturales, el gusto de ambigú y el placer compuesto y el gusto libertino de los varones veracruzanos. Finalmente, identifico las principales categorías morfológicas del gusto veracruzano.

Palabras clave: Cuerpo; Gusto; Antropología de los sentidos; Retóricas culinarias y sexuales; Morfología cultural; Veracruz.

${ }^{1}$ Una versión muy preliminar de este artículo fue expuesta en el curso de verano de la Universidad de Extremadura "Bocas compartidas: Alimentación, salud y tradiciones populares" (2006) bajo la dirección de Enrique Barcia. Agradezco especialmente las sugerencias y comentarios realizados entonces por Beatriz Muñoz, Manuel Gutiérrez y de Julián López. Igualmente agradezco los comentarios y oportunas sugerencias del dictaminador anónimo de este texto. 


\section{SUMMARY}

This contribution is framed on the theory and current anthropology of the senses, and in particular, tries to explore the sense of taste - the sensual taste- in the urban culture of Veracruz, Mexico. The article is an ethnographic study about the place that rhetorics and practices, related to food and sex, have in the society and social imagination from Veracruz. For this purpose, I take as reference my fieldwork during the 90s in this city. Stories and discourses are analyzed in an approach to understand the singular and hegemonic "cosmo-tasting" among the people from Veracruz. I focus my analysis on sociability, gastronomy and sexuality that engage the senses in veracruzan daily life. In particular, I study the sensory as identity rhetoric, the veracruzan meals as cultural world maps, the ambigu taste, the compound pleasure and the libertine taste from veracruzan males. Finally, I identify the main categories of morphological Veracruzan taste

Key words: Body, Taste, Anthropology of the Senses, Culinary and Sexual Rethorics, Cultural Morphology, Veracruz.

Para definir una cultura, se habla corrientemente de visión del mundo, haciendo así de la vista una primacía sensorial; también se podría asimismo evocar una gustación del mundo, habida cuenta de cómo las categorías alimentarias ordenan el mundo a su manera, comandan justamente el gusto de vivir. El hombre no se alimenta con alimentos indiferenciados: se alimenta ante todo de sentido. Comer significa participar de una cultura, compartir gustos y rechazos con los demás, preferencias e indiferencias, salsas, cocciones, etc.

(Le Breton, El sabor del mundo. Una antropología de los sentidos).

No hay ninguna razón para que una fantasía de mesa nos parezca menos extraordinaria que una fantasía de cama.

(D.A.F. de Sade, Justine o los infortunios de la virtud).

Desde que llegué a Veracruz, la ciudad se me presentó como una realidad de experiencia exotista - tropicalista- que yo tenía que degustar y hacer mío, incorporar de un modo literal, a mi escritura, a mi fisiología y a mi relación social. A pesar de ser un etnógrafo supuestamente alertado contra los peligros del exotismo, durante una parte de mi trabajo de campo me ví inmerso en el tropicalismo, la corriente ideológica, intelectual/estética, hegemónica en la construcción de la visión y algunos de los rasgos más importantes de la cultura urbana de Veracruz. Esto no fue ni mucho menos una estrategia de campo premeditada, sino que en un proceso involuntario "exoticé" a Veracruz al principio, la encarné sensorialmente. Esta internalización y encarnación exotista del tropicalismo, es el modo coherente - y canónico, incluso- reservado al forastero que quiere participar en la sociabilidad del Puerto, de ser aceptado en las relaciones interpersonales y sociales, y de ser reconocido como un sujeto que "saboreando", "oliendo", "mirando", e incluso "palpando" la ciudad, sabe "convivir" con los demás, además de formar parte de la autopercepción de la "identidad" local — del "ser veracruzano"- En aquellos momentos, y de modo imperceptible, su- 
frí un "adulzonamiento" del gusto y de mis palabras, una hipertrofia olfativa, un arrasamiento lumínico y multicolorista, en suma, la hiperexcitación sensorial propia del exotismo tropicalista ${ }^{2}$.

El presente texto versa sobre el sentido del gusto veracruzano, desde un enfoque crítico - y distanciado- de los sentidos y de la experiencia sensorial en este escenario. Pretende ser una reflexión sobre dos campos (la comida y la sexualidad) que convencionalmente han sido abordados en nuestra disciplina en la bisagra o haz de relaciones entre la naturaleza y la cultura: el gusto y los discursos referido a la comida (platos y bocados), y los deseos y prácticas sexuales en la cultura urbana del puerto de Veracruz, donde realicé mis investigaciones ${ }^{3}$. Se trata de una exploración e indagación, fundamentalmente etnográfica, sobre la presencia de estos discursos sensoriales en la sociabilidad y el imaginario urbanos de Veracruz, basándome en una selección de materiales etnográficos propios que se hallan dentro del campo de la estética nativa, de la morfología cultural de las gentes del Puerto de Veracruz. Me centraré de modo especial en las retóricas del gusto —en los campos de la sociabilidad, la gastronomía y lo sexual- que comprometen a los sentidos —una etnografía del sentido del gusto, enmarcada en una más amplia consideración de los otros sentidos-, a la imaginación social y cultural, y a las prácticas e interacciones sociales de esta ciudad. En mi acepción y con el uso del término "retórica", me refiero al conjunto de figuras, convenciones y reglas, cultural y socialmente determinadas, que generan las diferentes clases de representaciones —en este caso referidas al cuerpo en sus interacciones y relaciones sociales, a través de la comida, la comensalidad y la sexualidad-. Esta perspectiva permite una aproximación a los principios lógicos y las categorías estéticas nativas subyacentes a dichas retóricas, y que constituyen la trama singular de sentidos fluctuantes y operativos en esta cultura urbana ${ }^{4}$.

2 "Son las sensaciones una de las más firmes bases descriptivas del exotismo tropicalista. La percepción de un color, de un sonido, la suavidad de un paño, un aroma, despiertan un largo recorrido de emociones y correspondencias, pues además de la sensación por sí misma, lo que importa más son las correspondencias que ésta revela. Hay en el tropicalismo una fuerte corriente sensorial que ayuda al telón de fondo con acotaciones certeras" (Litvak, 1986: 177).

${ }^{3}$ Realizada en dos temporadas de campo, en 1993, y en 1996-97, en una investigación para mi tesis doctoral —publicada en el libro "Portales de múcara. Una etnografía del puerto de Veracruz" (Flores Martos, 2004). Mis informantes pertenecen a las clases medias y sectores populares de dicha ciudad, exhiben un marcado carácter urbano y mestizo, y viven en un contexto social y estético donde lo indígena no constituye una referencia central.

${ }^{4}$ Por otra parte, la opción metodológica de situarse en el campo de la retórica -elegida desde el inicio por el Grupo de Estudios de Etnología Americana al que pertenezco 
En otras tradiciones y sociedades es fácil detectar cómo la frontera entre la boca que se alimenta y la boca que ama es fluctuante. A través de los placeres de la boca se amplifican o rechazan los placeres del sexo (Châtelet, 1985: 167-168). Para los falansterianos —a la vez amantes y cocineros- y la teoría "harmoniana" de Fourier (1973), la variación culinaria prolonga metonímicamente la variación amorosa, apoyándose mutuamente. El trabajo de algunos etnólogos franceses —entre ellos las Mitológicas amerindias de Levi-Strauss-, constatan por otra parte la estrecha correlación mítica entre el acto de comer y la copulación.

Me interesa fundamentalmente el campo de la cocina de una sociedad, en el que sus miembros se encuentran negociando entre los imperativos de la naturaleza y de la cultura, tomando alimentos de su entorno y transformándolos para su consumo, pero siguiendo estrictamente sus categorías sociales de sentido, sus valores morales y estéticos. La "gustación del mundo" desarrollada por cada sociedad, contiene las formas y principios de su cosmología (Le Breton, 2007: 287). Abordando los sentidos y las retóricas sensoriales, se pretende abrir una senda hasta ahora menos transitada para acceder a los sentidos de esta cultura urbana.

La Antropología de los sentidos —más tarde denominada también "antropología sensorial"-, es una perspectiva epistemológica que ha logrado convertirse en una corriente o subdisciplina antropológica a partir de enfocar la importancia de los sentidos en la comprensión de las interacciones sociales y analizar los distintos modelos culturales que la experiencia sensorial - diferenciada según el contexto- construye. Supone una ruptura con la hegemonía de lo visual en la constitución de la razón y la ciencia occidental, y en particular de la antropología, favoreciendo la reconsideración de otros sentidos en el análisis de la cosmovisión, el lenguaje y la revisión metodológica de la construcción etnográfica. Se enfrenta con problemas epistemológicos y metodológicos referidos por ejemplo a los modos en que el etnógrafo puede retener, registrar y analizar las percepciones sensoriales de los "nativos" con los que trabaja, y las formas de "traducción" social y cultural entre las de ellos y del investigador.

Siguiendo a Paul Stoller, hay dos grandes enfoques dentro de la antro-

(http: //www.etnologiamericana.org/view/index.php)— permite y obliga a identificar las diferencias entre las formas retóricas americanas (criollas, mestizas y amerindias) y las occidentales/europeas de tal modo que estas últimas — las nuestras- no sesguen por completo la apreciación de la diferencia. En otras palabras, la retórica nos proporciona un instrumento que permite evitar la proyección sobre los materiales de trabajo de un logos unificado que acabe por convertir lo otro en lo mismo, y facilita abrirnos a la diferencia en la representaciones americanas e indígenas de la corporalidad y la persona precisamente en sus propios términos. 
pología de los sentidos. El que coloca el énfasis en el análisis en las informaciones etnográficas sensoriales ricamente descritas, y por otro lado, el que se centra en la comparación transcultural de información etnográfica sensorial y el desarrollo de teoría a partir de estudios de casos. Stoller también destaca que una reflexión crítica puede ayudar a que los antropólogos comprobemos las influencias que nuestras propias percepciones sensoriales tienen sobre la investigación (1989: 9). Los pioneros en estos trabajos han sido especialmente David Howes (1991, 2003, 2004) y Constance Classen (1993, 1997), y sobre todo es en los últimos años donde están cobrando un mayor auge los mismos 5 . Los estudios de antropología sensorial más influyentes y sólidos se realizaron en los años noventa enfocados en grupos culturales, revelando en qué medida los sentidos son interpretados y privilegiados de forma diferencial en diferentes culturas en tanto que modalidades de percepción y cognición. Actualmente los autores de esta corriente también están estudiando los movimientos sociales generados en los nuevos formatos culturales de las grandes metrópolis. Algunos de los trabajos influyentes en esta senda han sido los de Ackerman (2006), García Alonso et alia (1996), Goody (2002), Le Breton (2007) y Stoller (1989, 1997).

Veracruz se halla situada geográficamente en el Golfo de México, y sociocultural y estéticamente en pleno Caribe, y atesoró, durante algunos siglos coloniales, su condición de principal puerto continental de América y puerta de entrada y salida de gentes y mercancías. Se puede clasificar como una ciudad-puerto ya que el puerto se ha encontrado históricamente en la génesis, centro y dinamismo de la misma, y por sus décadas de constituir un puerto franco y un universo autónomo dentro del panorama mexicano. Nos encontramos ante una cultura urbana local con fuertes influencias y regularidades provenientes de su tradición hispana y occidental, donde el peso que la colonia española ha tenido en el siglo xx y mantiene en la actualidad, convierte a "lo español" en mucho más que una reliquia del pasado o en una rémora colonial.

Por otra parte, mantiene una posición privilegiada y excéntrica dentro del panorama de ciudades mexicanas, entre las cuales no existe ninguna semejante en morfología cultural o especificidad social (algo de lo que poseen una clara conciencia los veracruzanos, y quienes les visitan). Estando bañada por las aguas del Golfo de México, su constitución y ritmos internos se ven atravesados por contactos e influencias de otras culturas y sociedades caribeñas, con las que exhibe analogías considerables, y con las que históricamente mantuvo fuertes vínculos comerciales marítimos — hasta

\footnotetext{
${ }^{5}$ En 2006 se funda la revista The Sense \& Society, publicada por Berg (http: // www.ingentaconnect.com/content/berg/tsas).
} 
el siglo XVIII fue uno de los puertos y vértices claves del llamado Caribe Afroandaluz (García de León, 1992)—. Como otras ciudades de ese "Caribe" sociocultural —Nueva Orleans, Port-of-Spain, Miami-, presenta una fuerte densidad sociocultural —una alta concentración de diferencias, jerarquías y paradojas étnicas y sociales-, y un carnaval importante.

Debido a su carácter franco y actividad comercial, el Puerto de Veracruz ha sido durante la colonia y la época republicana, asiento de colonias de extranjeros: españoles, alemanes, italianos, franceses, norteamericanos, siriolibaneses, y en menor medida chinos y japoneses, que han tenido un papel activo en la economía y poder local, y una presencia numérica importante, al menos hasta el siglo XX. Conectado con este hecho, se identifica una fuerte provocación estética que lo extranjero ha mantenido y mantiene hoy en día en la ciudad.

Los jarochos como son conocidos los veracruzanos del Puerto en el resto e México —ellos se autodenominan jarochos, veracruzanos y porteños, de modo indistinto, excluyente o alternativo dependiendo del interlocutor y el contexto situacional de la conversación-, han sido modelados largamente por la óptica y mirada externa (nacional y extranjera), hasta perfilarse de modo nítido las características de su estereotipo en la cultura nacional. Se ha inventado una auténtica "fisiología nativa" del porteño, con rasgos definidos en lo corporal, lo emocional, lo sexual, que lo anclan en el terreno de las pasiones, la emotividad y el exceso. El ser alegre, fiestero, pachanguero se presentan como atributos sinónimos y consensuados de la identidad de los habitantes del puerto de Veracruz, formando parte, tanto del estereotipo de los "jarochos" en la taxonomía de la cultura nacional, como de su autopresentación identitaria.

La imagen del nativo americano primero, y del criollo que ha sufrido una "tropicalización del blanco" después, como "rey y señor de sí mismo" pergeñada por Américo Vespuccio (véase Litvak,1986: 147), a un tiempo esclavo y gobernador de sus pasiones —escribía Lezama Lima, "El barroco revela al señor en el puente de mando de su voluptuosidad"-, forma parte de ese exotismo tropicalista que Occidente ha venido proyectando sobre el continente americano. Existe una introyección por los veracruzanos, como revelan sus historias de locos y personajes, travestis, e historias libertinas y de excesos corporales ${ }^{6}$, de este estereotipo tropicalista, en las que se muestran controlando y sirviendo al mismo tiempo a sus pasiones y voluptuosidad, atentos a no dejar el menor deseo sin satisfacer. Estos rasgos del "cáracter" jarocho son así convertidos en "mercancía" de lo propio — de una

\footnotetext{
6 Para una etnografía y análisis del corpus mítico urbano de Veracruz, véase los trabajos de Flores Martos (1996, 2002 y 2004: 649-659).
} 
identidad jarocha, bajo las retóricas del tropicalismo- atractiva para pensarse a sí mismos, y proyectada ante los de fuera.

Así retrataba en 1948, Fernando Benítez, una noche de "convivio" y sociabilidad en Los Portales —una gran cantina al aire libre, como la denominó una de mis informantes - en la plaza central (zócalo) de la ciudad, abandonados en exceso a los deseos gastronómicos, alcohólicos, y sexuales (como se sugiere de modo sutil), y escenificando la máxima que apuntaba Sergio Pitol para caracterizar a los veracruzanos de "resistirse a un deseo, es vivir en el error"8:

¡La serenata veracruzana! Necesaria cura de reposo para el triste hombre de la meseta. Se vive al aire libre a medio vestir, con el apetito afilado y la cabeza trastornada, porque se ha recobrado plenamente la sensualidad y, con ella, la certeza de nuestra condición corpórea.

Abundan los cuadros pantagruélicos. Veracruzanos de enormes panzas y carrillos colorados no cesan de trasegar cerveza; gordas mujeres de comerciantes devoran descomunales fuentes de percebes y pescados; marineros negros y suecos atléticos de enmarañadas greñas rubias, se emborrachan hasta rodar bajo las mesas. En medio de esa humanidad glotona y bárbara, como aves que cruzan el pantano sin mancharse..., se mueven, llenas de gracia, las hijas de estas abigarradas y sudorosas matronas. (Benítez, 1992: 205).

\section{UNA CIENCIA PARA EL GUSTO (DE LOS ANTROPÓlOGOS)}

En buena medida el gusto ha sido considerado en la tradición occidental como el más "bajo" — quizás por tratarlo como el sentido "más corporal”, y con más carga de valoraciones morales - en la jerarquía de los sentidos en cuanto a la atención que la filosofía y el pensamiento occidental le han prestado. Sin duda ello ha contribuido a que los ensayos y trabajos tendentes hacia lo que podemos denominar tentativamente "una antropología del gusto", hayan sido muy recientes, y siempre al abrigo del desarrollo

7 La categoría nativa de convivir y convivio (a veces llamado también "conviviazgo") apuntan al núcleo central de la relación personal y social en el Puerto. Algo muy valorado y básico en las relaciones interpersonales es "saber convivir", una cualidad que condensa a la vez un respeto a la jerarquía ("dar su lugar" al interlocutor), y un reflejo de modulaciones y modales implícitos en las reglas del trato social. Participar en cualquier "convivio" (reunión o fiesta del grado que sea), implica habitualmente "tomar" alcohol y comida, y compartir conversación y tiempo con los demás (y muy frecuentemente música y baile también).

8 "El mundo veracruzano, como es bien sabido, tiene virtudes y gracias que los alemanes desconocen, pero eso lo hace, como a pocos, proclive a toda clase de tentaciones. Resistirse a un deseo, cualquiera que sea, significa una disminución, ser nadie, vivir en el error" (Pitol, 1996). 
creciente de una más general antropología de los sentidos. No es hasta los primeros años 90, y bajo la influencia de algunos trabajos de Mary Douglas, cuando se verbaliza el concepto "antropología del gusto" en los textos de Falk (1991: 757-790) y Lalonde (1992: 67-86), y cuando Jack Goody (1995) desarrolla su trabajo de sociología comparada sobre cocina y comida. Pero hemos de esperar hasta los trabajos de Korsmeyer (2002, 2006) para encontrar una indagación más integral y de mayor solidez para trazar un marco operativo para una antropología del gusto. En su estado de la cuestión sobre los estudios antropológicos y sociológicos enfocados en la comida y la memoria, Holtzman (2006: 361-378) identifica un interés creciente en abordar las comidas y las prácticas de comensalidad como formas encarnadas de memoria.

Si como propone Le Breton, "la cocina da cuerpo en doble sentido a los individuos, ya que también les imprime la sensación de identidad" (2007: 276), los discursos, historias y prácticas sociales relativas a las comidas y a la comensalidad insertadas en el flujo de la vida cotidiana, constituyen glosas, complementos y reelaboraciones de esos "cuerpos" moduladas desde su cuerpo social de referencia, pero también modelan —y matizan- los cuerpos de esos actores sociales desde la perspectiva más amplia de la "gustación del mundo" por la boca, la que "consume" comidas, cuerpos e historias - a través de la oralidad-.

El concepto de "gusto" tiene al menos dos acepciones relevantes para el análisis antropológico, ambas de construcción y conformación social y cultural: el gusto como substancia estética o sentido genérico que permite una vía de percepción y disfrute estético ${ }^{10}$, y el gusto como uno de los sentidos que proporciona una vía de percepción y disfrute más específicamente sensual. Es en esta última acepción desde la que analizaré el gusto veracruzano en estas páginas. Ese otro gusto veracruzano, como hábito y juicio estético de génesis y manufactura estrictamente social y cultural —en el sentido de formación social del gusto en Bourdieu (1988)_, y guiado por la necesidad y afán de distinción entre las clases y grupos sociales, ya fue analizado con cierto detalle en el capítulo "Sociales: Ecos de Sociedad" de mi monografía Portales de múcara (Flores Martos, 2004: 215-343), y de modo especial en su apartado "Clasificados: clubes en Veracruz"11.

9 "El gusto clasifica la percepción de los sabores antes de desbordar ese campo para englobar la preferencia por objetos o por una actividad. La gustación del mundo toma su vocabulario de la tradición culinaria”. (Le Breton, 2007: 268).

10 Sobre el mismo han reflexionado de modo intenso un filósofo —Kant (1999) - y un sociólogo —Bourdieu (1988) — desde posiciones radicalmente contrastadas.

11 "Desde una óptica global de conjunto, el panorama de la vida social y la sociabilidad veracruzana, a través de la yuxtaposición y copresencia de las diferentes etique- 
El análisis del gusto más sensual —comunitario, social-, en tanto que uno de los sentidos ${ }^{12}$, permite por otra parte una aproximación desde la lente etnográfica a la conceptualización de la estética nativa, y mediante la identificación y estudio de las categorías nativas del gusto proporciona una senda para trazar nexos con el estilo de la cultura urbana veracruzana. Asimismo, lo emplearé con el matiz más amplio que recoge una de las acepciones de nuestro diccionario de la lengua: "Placer o deleite que se experimenta con algún motivo, o se recibe de cualquier cosa" (DRAE, 1992).

\section{LO SENSORIAL COMO RETÓRICA IDENTITARIA}

En la construcción del estereotipo de "lo tropical" en Veracruz por los "viajeros" — como categoría amplia-, es patente lo que podríamos denominar una "hipertrofia del olfato y del paladar" en los textos, su orientación a una cata sensorial de la ciudad, y es factible la realización de una etnografía crítica de aromas y sabores. Por estos dos sentidos pasa la sugestión de la sensualidad tropical de la ciudad, la proyección "frutal" a sus mujeres y otros elementos sensibles, la experiencia de "embriagarse de Veracruz", es insertada en una enumeración barroca de elementos susceptibles de deglutir o incorporar sensorialmente, al tiempo que se incorpora el mundo ${ }^{13}$.

tas, gradaciones y agrupaciones-clubes sociales de la segmentación intrasocial de la ciudad, estaría paradójicamente representando lo peculiar y distintivo de esta cultura urbana, "lo propio" y "lo mismo" de ella: la hipertrofiada segmentación clasificatoria (en clases lógicas marcadas por un nombre o etiqueta) que existen y llegan a existir imaginariamente dentro de la endogamia social de Veracruz, porque los clubes veracruzanos servirían como una vía de distinción "para separarse", no del pueblo, sino de ellos mismos, de la homogeneidad, más o menos matizada, de las clases medias locales" (Flores Martos, 2004: 289).

${ }_{12}$ Así era definido por Brillat-Savarin en su Fisiología del gusto: "Llámase gusto al sentido que nos relaciona con los cuerpos sápidos, por medio de la sensación que sobre el órgano destinado a apreciarlos causan [...] Puede el gusto considerarse dividido en los tres órdenes siguientes: En el hombre físico, es aparato propio para apreciar los sabores. Respecto al hombre moral, es la sensación que en el sistema nervioso central excita el órgano de que se trata, impresionado por algún cuerpo sabroso. Por último considerado en su causa material, el gusto es la propiedad de ciertos cuerpos para impresionar dicho órgano, originando sensaciones" (1986: 42-43).

13 "El banquete literario, la prolífica descripción de frutas y mariscos, es de jubilosa raíz barroca. Intentemos reconstruir, con platerescos asistentes de uno y otro mundo, una de esas fiestas regidas por el afán, tan dionisíaco como dialéctico, de incorporar el mundo, de hacer suyo el mundo exterior, a través del horno transmutativo de la asimilación" (Lezama Lima, 1993: 41). 
Así expresa esta hipertrofia sensorial y gustativa, en este caso en forma de comunión de los sentidos, Juan Rejano, un español (cordobés) refugiado republicano, que llegó al Puerto en 1939:

Hasta las frutas parecen tenderme los brazos en este puerto hospitalario. Cada día hago una visita a los mercados para ver las frutas. A veces, voy solo; a veces, acompañado de algunos pintores, que están como embriagados por este derroche de colores. Estas frutas saben ofrecerlas los veracruzanos de muy distintas maneras: naturales, en helados, en refrescos. Y en ensalada. Quien no haya comido una ensalada de frutas en Veracruz, es posible que después no haya tenido facilidad para entrar en la vida lumínica de México. La piña, la guanábana, el plátano, los zapotes, el mango, la naranja, la papaya... que se yo... Una pirámide de radios rociada de miel y exhalando intensos aromas. Llevarse a los labios estas deliciosas pulpas es como ponerse en comunión con una naturaleza desbordante, áspera, misteriosa, fuerte, que lleva en su seno todas las ternuras. Es como tenderse en la tierra, una noche del trópico, a contemplar las estrellas, o como asomarse al mar en una de esas playas vírgenes, llenas de conchas solitarias y de pelícanos señoriales. Es embriagarse de la tierra de América ("La esfinge mestiza", 1992: t.IX, 205).

Otro refugiado republicano, Eduardo Ontañón, expresa también esta sensualidad frutal de los aspectos visibles y sensibles del puerto y el estado de Veracruz, la confusión de los sentidos ante lo que le rodea al viajero - fundamentalmente el de la vista y el gusto-, e insiste en el gusto como el sentido hegemónico para que el "regustador" pueda "paladear", "saborear" la ciudad. Así comenta, en el epígrafe Visita y saboreo de Veracruz:

Si hay una región, un estado sensual dentro de la República, ese es el de Veracruz, todo se goza con los ojos y paladar a la vez. Se gusta mientras que se está viendo. Podríamos decir que es una paisaje que se paladea, que se muerde como una fruta...Por sus calles hay también muy sugestivos itinerarios que paladear. Que paladear, puesto que ya hemos quedado en que fácilmente se confunden en esta ruta el goce de los ojos con el paladar (1992: t. IX, 239, 241-242).

Pero esta retórica sensorial, del gusto tropicalista no es privilegio de viajeros españoles. Otro autor, en este caso un periodista mexicano con intereses hacia la antropología, Fernando Benítez, en el relato de su estancia en este puerto en 1948, se apoyaba también en esos sentidos para describir la "invitación a la sensualidad" de la cocina veracruzana:

Un vaso de cerveza helada permite saborear la mejor primera docena de ostiones en su concha que se nos sirve entre rodajas de limón. El menú, por sí solo, es una invitación a la sensualidad: jaibas, camarones, cangrejos, langostas. No faltan los percebes olorosos a plantas marinas. Los pescados más finos figuran también en la lista: huachinangos pequeños de escamas sonrosadas; pámpanos de carne tierna y sápida; suavísimas mojarras de río; robalos y esmedregales. Faisanes y tórtolas baten sus alas sobre esta naturaleza muerta, necesaria prolongación de 
los caldos marineros y de las sopas de pescado con sus tonos ácidos, picantes, y su gama de sabores delicados. Los matices del ajo, del aceite de oliva, la intervención de las salsas de tomate y de "chipalchole", de las especias ya aclimatadas en el trópico americano, unidos a la fragancia de la nieve de guanábana y del aromático café, forman las principales delicias de la cocina veracruzana. (1992: t. XI, 203-204).

La forja del exotismo de "lo tropical" de Veracruz, va a pasar necesariamente por magnificar los aromas "frutales" de las mujeres jarochas —no es ningún azar, por tanto que uno de los términos con que en Veracruz se habla del sexo femenino (vagina) sea el de "papaya", una fruta local—, y por una hipertrofia del sentido del olfato, y del gusto del extranjero cautivado. Esto también queda patente en la novela "Intramuros" (1983), de un importante novelista veracruzano, Luis Arturo Ramos, que en el siguiente fragmento describe la seducción y sensaciones experimentadas por un español exiliado de la Guerra Civil, que descubre la sensualidad tropical en una mujer jarocha, con un énfasis especial en sus aromas:

Esteban quedó hipnotizado por los ojos femeninos y se entregó al síndrome del extranjero que huele por primera vez el entrepecho de la mestiza. Esteban absorbió con todos los sentidos el aroma que prevalecía a su alrededor, que envolvía a la muchacha como una segunda piel (Ibid, 171).

Como ya desarrollé en detalle en otro trabajo (Flores Martos, 2004: 6076), existe en el Puerto una vía de incorporación (literal) del exotismo tropicalista para el fuereño —en este caso yo como etnógrafo- que convive y busca insertarse en las redes de sociabilidad locales; esta "tropicalización del blanco ${ }^{14}$ " como fue llamada desde el siglo XVIII por la filosofía y pensamiento colonialista europeo, pasa por un proceso de mímesis e hiperexcitación sensorial, en el que el sujeto se asombra y es cautivado por determinadas imágenes, sabores, olores y deseos, al tiempo que desarrolla un gusto y una actitud corporal modelada por esa óptica y sociabilidad "tropicalista" que es pensada como la propia, como la característica de la identidad veracruzana y de los veracruzanos.

\section{Platos COMO MAPAMUNDI CULTURAL}

Ya desde el siglo XIX contamos con numerosos relatos de viajeros que al pasar por Veracruz dan constancia de la asombrosa riqueza de la cocina veracruzana incorporando elementos de las tradiciones alimenticias indíge-

${ }^{14}$ Corriente europea de pensamiento y denuncia moral sobre los efectos perniciosos del trópico en sus habitantes, y en los colonos y europeos allí instalados (véase Gerbi 1982: 734-739). 
nas prehispánicas, afrocaribeñas y españolas ${ }^{15}$. Durante mi investigación en Veracruz, tanto los disfraces y escenas de carnaval, los estereotipos de posesión espiritual y los platos de cocina "tradicional" veracruzana, han sido los campos o expresiones privilegiadas para analizar el trabajo cultural desplegado para la absorción y metabolización de la diferencia cultural y extranjería en el puerto de Veracruz, unas manifestaciones culturales que proporcionan ilustraciones sobre la imaginación, y encarnación sensible de lo extranjero en la ciudad.

La estética y la morfología cultural de la sociedad veracruzana, ha estado marcada desde época colonial hasta el presente, por la compulsión mimética por lo extranjero (Flores Martos, 2004: 354-357) —o si se quiere "gusto extranjerizante" o cosmopolita - expandido por toda la población, pero que aflora de modo más intenso entre las clases medias y altas porteñas —que hasta la requisa federal del puerto en los años 90 relatan el hábito de comprar alimentos y bebidas importadas de Europa-, hasta llegar a ser un rasgo prominente veracruzano.

La incorporación de lo extranjero, también tiene lugar en el terreno de la cocina y gastronomía veracruzana. Es en los diferentes platos de la cocina "tradicional" y "típica" del Puerto figuran desde el mondongo a la veracruzana, hasta los pulpos en su tinta, la paella, el pollo a la cubana, etc, donde se puede aislar y realizar un seguimiento de cómo los diferentes sabores, ingredientes, especias no oriundas de la región, son integrados entreverándose o no, en el gusto veracruzano. Así en las recetas de algunos platos veracruzanos, podemos ver desplegado una suerte de "mapamundi cultural" gustativo y sensible de la diferencia ${ }^{16}$, que ha sido compuesto en el devenir histórico de esta cultura portuaria.

15 Robalos, huachinangos, pámpanos, mojarras, pulpos, calamares, tortugas, chucumites, huevas de nácar o de lisa, en fin todos estos productos marinos pueden paladearse en la actualidad en chilpacholes, sopas y caldos largos, lo mismo que en ceviches y en cócteles al estilo de los "Vuelve a la vida". Guisados y revueltos con arroces y jitomates estos frutos marinos se preparan para hacer el famoso Arroz a la tumbada que recuerda los platillos del Caribe combinados con el aceite de coco, la yuca o el plátano frito. Pero a la hora de mezclar estos productos del mar con chiles, frijoles y masa de maíz, ya sea en tortilla o en tamal, aflora la vertiente de la cocina india. Ahí están por ejemplo las empanadas de cazón, o los tamales de bobo. El uso del maíz ha resultado imprescindible en la cocina jarocha Por su parte las alcaparras, las aceitunas, los garbanzos, las especies, las almendras, las uvas y el uso abundante de aceite de oliva y vinagre envían al paladar a las costas y tierras españolas. Pero ya van de regreso al puerto para paladear aquel inolvidable pescado a la veracruzana o la torta de mariscos, que son las primas jarochas de los preparados andaluces o canarios (Pérez Monfort, 1996a).

${ }^{16}$ Esta idea de enfrentar un plato como si de un mapamundi cultural se tratase, la he tomado de la etnografía americana del trabajo de Pedro Pitarch, y en concreto de la receta mestiza de Sopa de Pan que le proporcionó a este autor, doña Esperanza 
En mis estancias en Veracruz, se hizo evidente una fuerte presencia de "lo español" en el Puerto: costumbres, platos gastronómicos y bebidas. Si abrimos las páginas de clasificados y espectáculos del periódico El Dictamen cualquier domingo, y nos extravíamos en los múltiples anuncios de los menús dominicales de restaurantes, cafés, y hoteles, encontraremos repetidamente en esos menús un lugar privilegiado para algunos de platos más tradicionales de la gastronomía española, como diferentes tipos de paellas (la paella es el plato "español" más reiterado), fabada, caldo gallego, pulpos a la gallega, callos (a la madrileña, a la andaluza), la sopa y el cocido madrileño... La paella es un plato que actúa en cierto sentido como marcador étnico-nacional. Por un lado es un plato "español" festivo muy apreciado en Veracruz, sobre todo como comida dominical, llegando ocasionalmente a introducirse en el menú de una comida de boda de una familia "española"; también es una de las comidas que, junto con la tortilla española, se lleva a la romería de la festividad de la Covadonga por las familias de la colonia hispana que allí acuden. En Veracruz se tiene una conciencia relativa del origen (español) del plato, y de algunos de los ingredientes, proceso de cocción y presentación de la paella, aunque desde luego no del "punto" de cocción del arroz, que suele servirse pasado o deshecho — como se sirve el arroz en otros platillos locales-. Pero la paella alcanza un lugar como plato estrella en el gusto de las gentes de clase media del Puerto, y sirviéndoles de signo de distinción social y "buen gusto ${ }^{17}$ ". A mi pregunta

Hernández, una señora de la ciudad de San Cristóbal Las Casas (Chiapas, México): "En las casas indígenas las comidas se componen básicamente de maíz y frijol, preparados y combinados de muchas maneras. Pero a veces puede comerse también alimentos importados, por ejemplo una lata de sardinas, panecillos de trigo dulce o incluso queso; más lo más importante es que el maíz y el frijol no se mezclan jamás con la comida "de Castilla". Se comerá la tortilla de maíz, y luego, o antes, pero nunca al mismo tiempo, las sardinas o el pan; las "quesadillas" mexicanas, por ejemplo, son inconcebibles en una comida indígena. Por el contrario, todo en la cocina ladina delata su carácter mezclado. Tómese por ejemplo la receta de la "Sopa de Pan", el plato considerado típico de San Cristóbal de Las Casas: en una olla grande se pone una primera capa de pan blanco de trigo, frito en manteca de cerdo; una segunda capa de plátano macho, también frito; una tercera capa de verdura que se ha cocido por separado, que lleva ejote (judías verdes), cebolla, ajo, chícharos (guisantes), calabacita, zanahoria y papa (patata); una cuarta capa de huevo duro con jitomate frito; y a todo ello se le añade caldo de pollo con una pizca de tomillo, orégano y pimienta. Puede añadirse un poco de azafrán para dar sabor, y se sirve. Seguirle la pista a estos ingredientes proporciona un extenso mapamundi así como una extensa estratigrafía histórica, pero lo que me parece más significativo es que son concienzudamente mixturados hasta volver casi imposible su identificación singular" (Pitarch, 1995: 238-239).

17 Daniel Noriega se refería a un afamado periodista de la televisión y prensa locales, el Nacho Gómez, que en sus ostentosas apariciones en los restaurantes de Los Portales, sólo pedía paella y botellas de whisky de malta Chivas Regal. 
sobre “¿cómo hacen acá la paella?”, doña Mari18 me lo describía de la siguiente manera:

La paella. Pues mira, se compra un arroz especial de caja, para paella. Luego se pica cebollita, perejil, poquito, nada más para que le dé sabor, jitomate, poquitito y peladito. El arroz se sofríe con ajos, pero en puro aceite de oliva con los ajos, cuando ya empieza a sonar, entonces ya se le baja del fuego, se le quita un poco de aceite de oliva si es mucho, y se le quitan los ajos y ya...Ah pero, debe uno de tener el pollo en trocitos, hervido y frito, la carne de puerco, el camarón grande, dese langostino [cigala o acamaya] también, camarones... Se le pone pedazos de jaiba también, ya todo se le pone un poquito de color al arroz, pero a veces por acá se hace colorado, pero en otras ocasiones se le pone el azafrán, ese es el punto, el que da el sabor. Entonces ya está, tiene que ser en cazuela, porque sino no sale buena, de barro o una de metal. Y ya se pone a fuego lento a que esté...a que ya esté el arrocito y todo, ahí está una vigilando que seque bien el arroz, y eso es todo. Se sirve, ponen el limón partidito para el que quiere, y lo tomamos con vino blanco. Porque como tiene mucha fuerza la paella, pues ya con eso para la digestión, tomamos el vino blanco.

Como reverso de un plato tan valorado socialmente en la ciudad como la paella, doña Mari me hablaba del arroz a la tumbada, como un plato típico veracruzano:

Bueno el arroz a la tumbada, es un paella corriente, porque: lleva pescado frito, bueno el arroz, pescado frito, camarones, un poco de pollo frito, puerco también frito, ya cocido y frito. Y el chiste es que el arroz queda caldosito, no queda seco, queda caldoso. Hay un lugar aquí cerca, que se llama Alvarado, es de donde es tradicional el arroz a la tumbada.

Ahora miremos dentro de un plato hondo - de cuchara- como es el mondongo a la veracruzana, sus componentes, texturas y presentación, en las palabras de doña Mari de Córdoba:

¡El mondongo, la panza! Mira, mucha gente aquí acostumbra a comérselo en Todos Santos. Tripa, librillo, el callo, la pata, el hígado, el bofe le echan, todo eso lo hacen. Lo hacen en verde, y se hace en rojo. Entonces la salsa roja, se pone a hervir ya todo eso, ya que está suavesita, blandita, ya se pica, se parte la carne. $\mathrm{Y}$ ya que tiene uno, se pone a hervir chile ancho, tomate, ajo, cebolla, y todo

${ }^{18}$ Creo necesaria una aclaración formal relativa al modo de trascripción de los fragmentos de entrevistas y palabras de mis informantes. Se ha elegido -por diversas razones teóricas, metodológicas y estéticas- la transcripción literal y casi fonética de las entrevistas y conversaciones con mis interlocutores, relegando el criterio "ortográfico": se trata de pasajes orales que quiero sean reproducidos manteniendo en lo posible algo de su oralidad (la gente no habla como escribe, ni como dictan los volúmenes de gramática o diccionarios). En la literatura etnográfica esto se acepta cuando se trata de pasajes hablados por indígenas y campesinos, y en este caso, se aceptará para los "nativos" del Puerto, sean personas de clases altas, medias, de extracción popular o marginal. 
eso y se licua con un poco de pimienta, y ya se sofríe ese guiso. Se le ponen aceitunas, bastante aceitunas, pedazos de papa blanca grande, esas las papas a lo último porque sino se van a romper. Y ya se le incorpora la carne, con el caldo, y hoja de tomillo y hoja de laurel (aquí se usa mucho el laurel y el tomillo). Y entonces ya que está ¡hirviendo eso, ya!, ya se acitrona, ya que agarró el sabor, ya que le da a uno el olor, al acabar, se ponen las papas a lo último. Y eso es todo. Si quieren picoso, se le pone chile de árbol dese, picosísimo. Y si no, se hace aparte ahí el chile, y ya le ponen, chile seco molido. Se come con tortilla, arroz blanco o arroz colorado y aceitunas.

A modo de glosa de sus ingredientes, conviene indicar que en la ciudad se tiene conciencia del origen español de las aceitunas - alimento festivo muy apreciado y caro- y las especias mencionadas (y de algunas presentes en otras recetas de mondongo como los cominos o el orégano), pero también del aceite de oliva, que intervienen en el plato. Es importante constatar que se trata de un plato que se hace necesario explicar, contar al "fuereño" —aunque éste sea un español habituado a los callos- de qué está compuesto y la manera en que se come. Así Doña Mari me explicaba que se les debe estrujar abundante limón y de un platillo que tiene cebolla muy picadita y chile verde pequeño — chile piquín—, se sirve uno al gusto cebollita y chile verde piquín; se remueve en el caldo para que el chile suelte el sabor, y el mondongo se ponga picoso, que es como debe ser tomado; o me contaba cómo lo toman los hombres al día siguiente de una desvelada o juerga, y de estar tomando/chupando, para quitarse la "cruda" (resaca): lo toman bien picoso y se ponen a sudar, y así eliminan la cruda. La manera de comerlo es haciéndose un taco con los trozos del mondongo.

Pienso con Lévi-Strauss (1981) que la digestión ofrece un modelo orgánico anticipado de la cultura. Los trabajos de Andrade (1928), Bachelard (1982), Bajtin (1987) y Châtelet (1985) sirven también para mostrar como el concepto de "digestión" ilumina mecanismos claves del funcionamiento y tránsitos del cuerpo individual, social y de la dinámica de una cultura, en relación a la transformación de lo diferente o su profunda interiorización, en un proceso de metabolización o digestión cultural de esa diferencia. De modo especular, conviene reflexionar sobre la afirmación: "la glotonería (cultural) es una afirmación del principio de identidad".

\section{Gusto De AMBigú y Placer COMPUESTO}

La frase e idea de "servirse al gusto", se revela como una seña de identidad y particularización de gusto veracruzano, tanto en el ámbito de lo doméstico y privado - en las mesas de las casas en las que viví, con las familias Córdoba y Morgado, entre otras-, como en el campo de lo público. 
De modo más intenso en las neverías (heladerías) del centro de Veracruz, es patente esta exhibición del "gusto" individual y particularizado en lo público. A la puerta de estos establecimientos e interpelando a los viandantes, se vocea la amplia oferta de "nieves" de sabores de múltiples frutas: guanábana, guayaba, mango, zapote, mamey, limón, coco, naranja, piña, papaya, etc., con la fórmula “iPásele güero ${ }^{19}$, pásele güera, pásele!!”, referidas a los paseantes, que ocasionalmente deciden entrar a comprar un sabor que les antoje. Se mantiene así la tradición de pregonar o vocear estos mensajes que incitan y comprometen al gusto, en el ámbito de la calle, de lo público —el gusto, en este caso, del sujeto asediado por la múltiple oferta de sabores de frutas de las nieves voceadas-.

Este gusto particularizado o individualizado, también se exhibe de modo privilegiado en el Café de La Parroquia —el café paradigmático desde un punto de vista histórico, social, de estilo de llevar el establecimiento en la ciudad, y de prestigio para las clases medias y acomodadas veracruzanas, inmortalizado por García Márquez en El amor en los tiempos del cólera-, creado y llevado por "españoles" del Puerto (la familia Fernández). Con la siguiente descripción e historia del estilo y singularidad de este café, lo perfilaba Jose Luis Gómez, asiduo del café:

Durante mucho tiempo, estos señores Fernández han tenido un estilo muy particular de llevar el café, muy clásico, muy típico. Estos amigos no hacían fritanga, no hacían gorditas ni picadas, y entonces mucha gente las llevaba de la calle, pedían el café y la fruta, y ahí se comían las picadas. Y pues le ponían el plato, y le ponían los tenedores, y no le cobraban nada, nada más le cobraban el café y la fruta. Inclusive algunos tipos folclóricos, de aquí de Veracruz, que hay mucha gente folclórica, confianzudos...yo conocí a dos, queda uno vivo. Uno de ellos, que era muy amigo de ellos, era un hombre muy servicial, una gente agradable de la cual tengo yo un muy grato recuerdo, don Antonio Vigorito, hijo de italianos, ese señor ise metía a la cocina a hacerse su comida porque le gustaba de cierta forma!, y era amigo del cocinero, iy pagaba, pagaba todo, vaya!. Pero él entraba a la cocina a hacer su cosa. Hay otro, muy amigo de ellos también, ique les lleva la carne!, y saca el envoltorio del papel, "Quiero que me hagan este filete tres cuartos", ¡Y se lo hacen, y se lo hacen! ¡Y todavía los regaña porque se lo pasaron, o porque se lo dejaron crudo, y se los regresa! O sea es una cosa de un trato muy especial, muy, casi familiar podríamos decir.

La Parroquia aparece como un espacio donde el gusto del individuo, es manifestado y satisfecho incluso por encima de las normas del establecimien-

19 "Güero" o "güera", son términos parar referirse a un tono de piel claro en México, que además en Veracruz suelen tener un matiz cariñoso y evidenciar un gusto y prestigio sociales hacia la persona así aludida —en conexión con las valencias positivas coloniales y postcoloniales existentes en un modelo ideal de piel blanca- 
to. Estos ejemplos y casos, destacan el egoísmo e individualidad de los que hacen gala cada parroquiano, en un marco de gran convencionalidad social como es el café. Podemos enmarcar en esta línea del gusto individualizado en este café, el énfasis que ponen los cafetómanos en sentarse siempre en una mesa en que les atienda "su" mesero: el que sabe sus gustos y les conoce, el que ni les pregunta, y con el que gran parte de la comunicación tiene lugar a través de señas minúsculas, a veces imperceptibles.

Para "nombrar" este tipo de gusto particularizado, ante una oferta muy plural que es desplegada ante los sentidos, he elegido el término "gusto de ambigú ${ }^{20 "}$, siendo ésta una categoría nativa habitual para los veracruzanos. Los ambigús a los que asistí en el Puerto —en clubes sociales, fiestas de graduación profesional, o fiestas de cumpleaños-, tanto en escenarios domésticos como en salones contratados, constaban de una o varias mesas sobre la que se colocaban de una vez los diferentes platos y comidas, siendo ofrecidos al mismo tiempo a su elección, y ante los cuales los invitados pasaban para servirse a su gusto. Algunas "personas conocidas" porteñas - miembros significativos de las clases medias y altas, de tradición familiar en la ciudad y que tiene un peso público en la misma-, con una vida social activa, se referían en broma a que "Hay quién dijo que se podía definir Veracruz como la cultura del hambrigú", empleando "hambrigú" como un albur del término "ambigú", para referirse al gusto por comer, a capricho y en abundancia, que parece presidir cada acto social y fiesta de Veracruz.

Este gusto de ambigú también pude constatarlo con la experiencia de recepción de mis informantes veracruzanos ante un desfile de carnaval y el ambiente festivo de los Portales, por lo que es posible extraer una reflexión sobre la peculiaridad del gusto jarocho: ante una variedad que se le ofrece en un escenario público festivo, como en un "ambigú" compuesto de "platillos" estéticos, musicales, corporales, gastronómicos dispuestos a la vez a los sentidos (vista, gusto, olfato), el veracruzano selecciona y se sirve "al gusto" en su "plato", sin experimentar la confusión y saturación del observador fuereño o extranjero. Un gusto público de "ambigú", que por la valorización otorgada por los porteños a los aspectos sensibles constituye una suerte de "placer compuesto ${ }^{21}$ " experimentado en ambos escenarios festivos,

${ }^{20}$ El Diccionario Panhispánico de Dudas (2005) define "ambigú", como la adaptación gráfica de la voz francesa ambigu, que se usa en español con los sentidos de "comida compuesta de platos normalmente fríos que se sirven todos a la vez y espacio donde se disponen 'y 'lugar de un local de espectáculos donde se sirven bebidas y cosas de comer'.

${ }^{21}$ Este concepto de pasión o placer "compuesto" tiene su génesis en las obras de Charles Fourier (1973) y de Brillat-Savarin (1986), y un desarrollo crítico y teórico con Barthes (1977, 1987), remarcándose en todos ellos un sistema eufórico de lo mixto. Según Fourier (1973: 209,212) la pasión compuesta —una de las pasiones mecanizantes 
un placer sobredeterminado por varias causas simultáneas, entre las que no tiene sentido distinguir cuál conlleva el goce, importando únicamente que el individuo ya no sabe de dónde viene ni lo que quiere, excepto gozar (Barthes, 1987: 316).

Este gusto de ambigú y placer compuesto, donde una yuxtaposición de motivos comprometen al mismo tiempo a diferentes sentidos, tiene lugar también en las cantinas porticadas de los Portales, en la plaza central de Veracruz, como describía Fernando Benítez, hace que los sentidos se vean exaltados "como el vino de las campiñas mediterráneas":

¿En qué sitio de México es posible advertir las escenas que se desarrollan en la plaza de Veracruz? El palacio del Ayuntamiento, con sus blancas columnas y su airosa torre, es, en la tibia noche, bajo las estrellas resplandecientes, una decoración teatral, en la misma medida que lo son los portales vivamente iluminados y los árboles del jardín de recortadas follajes. Suenan sin cesar las guitarras costeñas, los sones jarochos y las marimbas. La música en sordina de la banda municipal, llega por rachas. En este aire estremecido se confunden los gritos de los vendedores, las conversaciones de los parroquianos, las disputas de los marineros, las charlas de los pájaros desvelados, y de las muchachas que pasean devolviendo saludos y requiebros. Pero este bullicio no altera los sentidos, sino que los exalta, como el vino de las campiñas mediterráneas" (Benítez, 1992: 201-207).

La singularidad de este goce "compuesto" y "gusto de ambigú" que tiene lugar en los paseos del carnaval y en el ambiente y sociabilidad de Los Portales y en otros espacios públicos (avenidas, plazas, calles), donde se acomodan y agolpan cientos y miles de personas, parece ser un rasgo de otras sociedades caribeñas como la portorriqueña. Rivera (1990: 7) trata el fenómeno de los "festivales comunales", señalando que se han convertido en hegemónicos en las celebraciones de Puerto Rico, y donde se exhibe un goce sensorial social, y múltiple.

Trabadas con este goce sensual, compuesto y de ambigú veracruzano, se encuentran sus formas - y en ocasiones géneros- de habla, trufada de lo que podríamos calificar como léxico libertino, y de metáforas gastronómicas para aludir y representar prácticas sexuales. Este léxico libertino o del exceso se acentúa después de dejar el mundo de los eufemismos, de las correcciones y buenas maneras, de la contención de la expresión y la grosería, que reinaba en sus casas familiares, donde todo lo dicho está en mayor

junto con la "mariposeante" y la "cabalista" - consiste "en una fogosidad ciega, un estado de embriaguez y de entusiasmo que nace del conjunto de varios placeres sensibles y anímicos experimentados simultáneamente...nace del conjunto de varios placeres de un solo orden, todos sensuales o todos anímicos.". Barthes (1977: 109) caracteriza esta pasión "compuesta" —o "romántica" - de Fourier como la pasión del desbordamiento, la exaltación (sensual o sublime) y de la multiplicación." 
o menor medida modulado por la presencia de madres, hermanas, esposas, compañeras, suegras y niños. Es cuando se abandona por unas horas este contexto, o se crea un espacio "de varones" en el jardín, cuando explotan en las conversaciones las fantasías, los deseos, entre estos hombres jarochos de clase media que conocí.

Las escenas e imágenes que se desarrollan en estas historias, las sitúan en ocasiones dentro del campo de lo grotesco, mostrando a unos protagonistas y personajes en su calidad de cuerpos inacabados, deseosos de engullir al otro ${ }^{22}$, de "comerse" a otra persona como metáfora - y eufemismode poseer sexualmente a ese otro, de incorporarlo. En el habla alburera porteña, "comerse a otro" equivale a "cogerse a otro" — mantener relaciones sexuales con él- Se despliega así una singular comensalidad, sexual y festiva para el hablante/deseante, repleta de metáforas gastronómicas que revelan tanto una erótica y sexualización del acto de comer/"coger", como una corriente de carnavalización de la comida y el sexo ${ }^{23}$, al mismo tiempo.

Una de estas expresiones, "No te la vas a acabar", se utiliza tanto para referirse a una comida presentada ante alguien, como con un sentido de desafío o invitación sexual. Un varón puede, en broma, retar a otro utilizando esta frase, sugiriéndole que no va a poder satisfacer sexualmente a una determinada mujer; también una mujer puede bromear con un hombre que le atrae o que incluso es su amante, retándole antes de mantener relaciones sexuales con él (y al mismo tiempo animándole), y refiriéndose a sí misma decirle: "No te la vas a acabar!" (como si fuera un plato de comida, o una botella, que uno es incapaz de vaciar, de consumir hasta el final). Cuando quien habla, por ejemplo señoras de clase media —doña Elsa, doña Mari, doña Guadalupe Montalvo, Marina-, aluden al tema sexual, de la forma eufemística con que se elude este tema incómodo para las formas sociales, puede describir de forma "decente" —y burlona al tiempo- la infidelidad o "aventura" de un hombre diciendo "se echó al plato a fulanita",

${ }^{22}$ Así definía el cuerpo grotesco, y su singular encarnación de un gusto social/cultural, Mijail Bajtin: "El comer y el beber son una de las manifestaciones más importantes de la vida del cuerpo grotesco. Los rasgos particulares de este cuerpo son el ser abierto, estar inacabado y en interacción con el mundo. En el comer estas particularidades se manifiestan del modo más tangible y concreto: el cuerpo se evade de sus límites; traga, engulle, desgarra el mundo, lo hace entrar en sí, se enriquece y crece a sus expensas...el hombre degusta el mundo, siente el gusto del mundo, lo introduce en su cuerpo, lo hace una parte de sí mismo" (1987: 252-253).

${ }^{23}$ Recordemos que para Bajtin son siete los motivos sobre los que actúa la carnavalización, a los que denomina "series carnavalizadas": el cuerpo, la vestimenta, la comida, la bebida, el sexo, la escatología y la muerte (Bajtin, 1987; Huerta Calvo, 1989: 26). 
"ya se comió su torta" o "ya se comió su loncha ${ }^{24 ", ~ a l u d i e n d o ~ a ~ q u e ~ e l ~ v a r o ́ n ~}$ ya quedó satisfecho sexualmente con una mujer, e implícitamente, ya está a la búsqueda de otra. De este modo tan plástico, expresaba Daniel N., lo imposible que es "acabarse a una vieja (mujer)":

Por más cosas que le hagas a una vieja y trates de complacerla, igual no te la vas a acabar. Le puedes comer la papaya, meterle el dedo por el culo, que te mame la verga y un chingo de cosas, pero no vas a poder satisfacerla del todo.

Para algunos de mis informantes, como Héctor N., los "palos" —expresión coloquial vulgar equivalente a "polvos" o coitos - tienen "sabor", y saben mejor "cuando te quieres vengar de una vieja [mujer]":

Antonio si sabes que hay un paso muy corto del amor al odio, y que cuando una mujer te hizo una mala jugada, o te enteraste que anduvo con otro, cuanto luego te reclama que le des más después de estar con ella. O sea, que la vieja te reclama que te la acabes, que la cumplas vaya. Y entonces tú te la coges, pero con ese odio hacia ella, entonces, iiiPuta!!!, ese palo sabe mejor que ningún otro.

Otra expresión muy veracruzana es "atender" y "sentirse atendido", en escenas que tienen que ver con la sociabilidad del convivio, la comensalidad, la fiesta, y las relaciones de amistad y sexuales, y precisamente por trenzarse por diferentes elementos, da lugar a una suerte de "placer compuesto". Por ejemplo el modo en que un anfitrión atiende a sus invitados a su fiesta. También se utiliza "atender" en un sentido estrictamente sexual, como sinónimo de mantener satisfecha sexualmente a su pareja, entendiéndose que como una obligación inexcusable dentro del matrimonio el que el varón atienda a su esposa, y viceversa, y sancionándose el no "atender" con la justificación social y comprensión ante las infidelidades y el mantenimiento de relaciones sexuales "por fuera", con otras personas.

En el caso de las meseras (camareras) que trabajan en las cantinas o fondas de la ciudad, los varones veracruzanos utilizan el término de "atender" o "sentirse atendidos" en los dos sentidos de la comensalidad y conviviazgo (como servidoras de comida y bebida), y el sexual (como cuerpos accesibles a sus deseos sexuales). Así expresaba Enrique F. su deseo de ir a una cantina de Circunvalación, después de conocer a dos de las meseras que trabajaban en ella una madrugada, y con las que había coincidido comiendo unas tortas: "Vamos a que nos atiendan. Y a lo menos un dedo, un dedeo con ellas". Por los comentarios de otro informante, Romeo, sobre su cantina preferida — "La Garlopa”- una de las cosas que más pesa

24 "Torta" como palabra equivalente a nuestro bocadillo, y "loncha" — por derivación del término inglés "lunch" - apunta a un refrigerio o bocado breve y portátil. 
en la elección de ir a una cantina o a otra, es si hay chavas (que trabajen como meseras, camareras) guapas o "de buena pierna", con las que cotorrear y sentirse "atendidos", con las que vacilar o fantasear erótica o sexualmente, y en su caso, realizar un "dedeo 25 ".

En esta ciudad, la comida cumple el importante papel de proceder a la restauración del cuerpo libertino tras los excesos. Comiendo y digiriendo un mondongo, sus degustadores proceden con este plato, que describíamos arriba, a una restauración corporal después de una noche de desvelada y exceso alcohólico, como un paso aconsejable para recuperarse de la fiesta. En el guión local de lo que es una noche festiva, importa mucho el acabarla yendo "a tomar un mondongo", como si una verdadera juerga no pudiera ser completa, ni relatada como tal, si no acaba con su consumo por los que han convivido juntos durante esas horas. Armando M. insistía en lo que experimenta al comer mondongo: "eso bien que levanta a un muerto, sirve para revivir a uno, y sobre todo para la cruda [resaca], bien picoso lo toma uno y siente así como escalofríos, siente uno revivir vaya”.

Enrique F., después de comentar su lance sexual con una "morena" (con la que relataba mantuvo un coito anal en su coche, y en presencia de otra mujer), además de enunciar algunos "bocados" como restauradores del exceso (la leche de mujer que mamó un rato, y un "caldo de langostinos y de acamayas, ipara amacizar!”), está construyendo su cuerpo como una suerte de cuerpo libertino. Elabora un discurso sobre las delicias del placer sexual, y de su fortaleza actual después de no haber dormido durante la noche ni durante el día, explicándolo por haber mamado la leche que le salían de sus pezones a la chica (tenía un niño pequeño), "así todo blanco y dulce", y por haber "amacizado" tomándose un caldo de acamayas y langostinos que le preparó su madre por la mañana. Él presenta estas dos sustancias como poderosos reconstituyentes físicos, anímicos (e incluso morales) de su cuerpo libertino ${ }^{26}$.

En cuanto a la imaginación social veracruzana sobre el comer y el "coger", podemos distinguir entre dos categorías, y sus valoraciones morales y emotivas relativas a:

${ }^{25}$ El término "dedear" o "dedeo" se utiliza en el habla de los varones del Puerto, para referirse en la introducción de algún dedo en la vagina o el ano de una mujer.

26 Así describe Henaff (1980) el funcionamiento económico del cuerpo libertino: "la comida en efecto debe reconstituir las fuerzas perdidas en la orgía, y la enunciación de esa reconstitución se hace a partir de ahí tan esencial como la de la escena del goce. El momento de la comida no es un elemento narrativo secundario, decorativo: es al contrario un tiempo fuerte de la narración, en la medida en que el único sujeto de ésta es el cuerpo libertino; decir la comida, representarla, es decir uno de los modos fundamentales de figuración de ese cuerpo, es asegurarse su mantenimiento textual, puesto que toda su historia posible es repetir su goce renovando sus fuerzas". 
a) El comer/coger de todo y en exceso: los "comegente". Existe en la ciudad una valoración muy negativa a la idea de "coger de todo" - mantener relaciones sexuales de modo indiscriminado-, animalizando la conducta de aquellos que supuestamente lo hacen —llamándoles por ejemplo "chacales $^{27 "}$ a los chicos jóvenes de las colonias populares periféricas-, o nombrándoles como "comegentes" para aludir a su orientación bisexual —en especial a los embarcados o marinos griegos, capaces de "comer" carne de varón y de mujer-. En el caso de la "gente de las colonias" aflora una subalternidad adjudicada a los sectores pobres y marginales, inscribiéndola en unos gustos - y usos - sexuales, corporales y morales mercenarios y estigmatizados. Hay un claro repudio cultural a esa glotonería corporal —al "comer en exceso" y al "comer de todo" (Le Breton, 2007: 283).

b) El "comer"/coger sólo carne y cuerpos extranjeros: las/os "gabacheras/ os". En el habla coloquial de Veracruz, se denomina "gabachos" a los norteamericanos y, por extensión, al resto de extranjeros occidentales. "Gabachero/a" remitiría a su dedicación y gusto por frecuentar el trato (amistoso, sexual) con personas extranjeras, llegándose a convertir en algunos casos en una compulsión, modus vivendi o en una dedicación casi exclusiva. Se les llama "gabacheras" a las prostitutas portaleras que están especializadas en ofrecer sus servicios sexuales a extranjeros y específicamente a embarcados (marinos). La prostituta gabachera estaría representando de forma inquietante para estos varones veracruzanos, el cuerpo femenino deseable ofrecido, entregado y poseído por el extranjero. Pero también son "gabacheros/as" personas de distintas dedicaciones (guías de turismo, músicos, oficinistas, bohemios y desocupados) que dedican una buena parte de su tiempo y energía a conocer, salir y mantener relaciones sexuales con extranjeros y extranjeras que se encuentran haciendo turismo y de paso por la ciudad.

\section{UN GUSTO VERACRUZANO LIBERTINO}

La compostura social modula el gusto veracruzano hacia lo que podemos etiquetar como una valoración positiva de "lo familiar", abominando

27 Se les llama así a los jóvenes dedicados a la prostitución no amanerados, ni travestidos o vestidos con ropas femeninas. Daniel N. me proporcionaba la siguiente descripción, un ejemplo del cruce - y contaminación- que se produce entre la taxonomía zoológica y social en el Puerto, al referirse a figuras de manifiesta subalternidad corporal que "comen de todo": "Aquí le dicen, a los prostitutos hombres, les dicen chacales. El chacal es como un lobo, o un coyote, como un buitre, o sea que come carroña, el chacal es lo peor. Los chacales, de la zona de allá, de las colonias, esos se dedican ja lo que caiga, mano! Ahí hay muchos chavos desos, en el parque Zamora, y también trabajan en los portales pero de una manera muy clandestina." 
de cualquier acto que pueda ser calificado de escándalo — “quemón”—. Así el término "familiar" referido al ambiente de algún establecimiento, alude a características como tranquilidad, seguridad, y de acceso apropiado para parejas y grupos de personas y amigos. En cambio se sobreentiende que los locales que explicitan en sus neones o publicidad el término "ambiente familiar", se caracterizan paradójicamente por un ambiente "pesado", donde la embriaguez, la prostitución, las peleas o robos son las notas dominantes. Se puede hablar de la existencia de unas retóricas de "lo familiar" en este escenario portuario, que contribuyen a ocultar las interacciones que tienen al cuerpo como objeto de transacción sexual y comercial, fundamentalmente en el campo de la prostitución abierta pero "camuflajeada" (Flores Martos, 2002: 38-42).

El gusto veracruzano de los varones con los que trabajé es marcadamente libertino. Libertino es quien vive para cumplir sus deseos, sin preocuparse por los demás y en especial por los objetos de dichos deseos. Para el libertino, solamente los sentidos imponen al hombre su condición humana, y el placer sensorial se convierte en la norma de todo tras la fuga de los otros valores. La sensación adquiere un lugar privilegiado en el juicio del libertino, que pasa a "juzgar todo por las sensaciones".

De este tipo de conformación de gusto "libertino" veracruzano, de carácter social y cultural en Veracruz ${ }^{28}$, es un ejemplo el siguiente fragmento de entrevista con Daniel N., relativo a su modo de tratar a las mujeres y lo que más le gusta de ellas:

Está cabrón el pensar que puedes darle a una vieja todo lo que ella necesita [en el sexo], no puedes acabarte a una vieja. Yo por eso no pienso en que se venga [en que se corra], en esperarla, no pienso nada más en mí. Me las cojo de manera gacha [mala], y aún así me dicen: "QQue chamba tan buena me hiciste, mi amor!. Sabes que son las dos cosas que más te gusta que te haga una vieja, con las que ya valiste verga. Una es que se beba tu semen, que lo saboree despacito y que le guste, que te vengas dentro de su boca. Me ha tocado conocer viejas que eran muy mamadoras, se ponían como locas con la verga, era como su juguete al que querían mamar. La otra es que le hablen a tu pito, y que le digan: "¡Oye, párate mi amoooor!".

Otro de mis informantes, Armando M., ejemplificando la fantasía y práctica veracruzana del "placer compuesto" o sobredeterminado, me explicaba por qué los cubanos que llegaban a la ciudad, quedaban encantados con las mujeres jarochas por ser éstas "muy calientes", y se detenía en glosar que cosa era eso de "chingar por las tres bocas":

\footnotetext{
${ }^{28}$ Véase mi trabajo "Hacia una teoría cultural del trauma y la violencia cotidianas en el Puerto de Veracruz" (Flores Martos, 2005).
} 
Los cubanos, cómo le gustan las mujeres de aquí, son muy calientes disen, te hasen unas chambas ¡de aquellas!. Si, "Chico, Mamá y Papá". Si hombre, "chico" es el chiquito, el que yo te diga, el chicapulas, ese es el chico... "Mamá" es una mamada, y "papá", es que ella se trabe completa por la papaya. Así que por las tres... Que la chingue, pero por las tres bocas, sî" (Armando M.).

Unas palabras sobre las fantasías de los varones veracruzanos y lo que podríamos llamar un glosario —y prácticas_ "culorientados". Durante mi trabajo de campo pude identificar la existencia de una ambivalencia o doble discurso del jarocho con respecto al "culo" — cuyo término se evita utilizándose otros términos alusivos o eufemísticos como nalgas, nalgón, pompas, cola, rabo, sisirisco, etc..-, en especial sobre el culo de la mujer:

- En el discurso grupal y en la sociedad, se desprecia como algo repugnante hasta incluso su pronunciación (el pronunciar la palabra "culo" es signo de ser muy grosero, y sobre todo de estar borracho o drogado), y desde luego la idea de su contacto/penetración — con la lengua o el pene-.

- En el discurso individual del varón, en la formulación del ideal de mujer jarocha y del cuerpo deseado, las nalgas o culo, (y por extensión el ano), es el objeto de deseo que aparece como más subyugante para el jarocho.

Destaca una suerte de fetichización del culo $^{29}$, hasta llegar a utilizar el término (prohibido en las interacciones sociales habituales) en conversaciones amistosas o con confianza de varones, y mediando bebidas alcohólicas, como una metonimia de la mujer: "No hombre George, los mejores culos están allí en el Bulevar" (Raúl A.).

Resulta cuando menos paradójico, el deseo velado y fuerte atracción que manifiestan los varones jarochos a comer o degustar lo que expulsa el culo de una mujer — ya sean excrementos o pedos-. Raúl A., contaba una anédcota de un viejo "maniático", de unos ochenta años y vecino suyo, que le gustaba ir con muchachas de 18 y 19 años, y que decía de esas mujeres esbeltas y bellas, "que bebían champán, y cagaban bolitas de chocolate". George C., en otra ocasión piropeaba desde su automóvil a una mujer del

29 Enrique F., solía repetir cuando se emborrachaba, o cuando se fijaba en una mujer atractiva por la calle: — “iCulo, mátame a pedos, que quiero morir jediondo!!”, o "El pedo, es el suspiro de un culo enamorado”. Para este informante estaba muy clara la jerarquía del deseo de los órganos sexuales femeninos, manteniendo el culo el mayor grado de deseo —así como su obsesión por penetrarlo con la lengua-: "El ano y el clítoris es lo máximo, olvídate de los labios mayores y de los labios menores... Y a veces dan ganas de meterle la lengua en el culo a la vieja, y iiiah su meechaaa!!!”. 
siguiente modo: “¡Ay mamasita, que buena estás! ¡Nenita me haría unos taquitos con tu caquita!".

Junto a esta imaginación masculina "culorientada", también existe una exaltación de las prácticas sexuales orales ("el beso polaco", o "beso-po-laco-la", como se refieren al beso negro que la mujer le da al varón), y en especial la felación. En mis entrevistas con varones son reiterativos los pasajes e historias que versan sobre mujeres "mamadoras": algunas reciben la etiqueta de "mamadora oficial" por alguno de los varones, que se jactan de sólo mantener con ellas este tipo de práctica sexual y no "ensartarlas" (penetrarlas).

Esta compulsión también era compartida por don José O., octogenario entonces, que expresaba así su gusto, en una glosa del "francés" como práctica sexual:

De siempre, no nadamás ahora, siempre han existido tres tipos de sexo. Ya se los encontraba uno en el Salón México allá por los cuarentas, y en los bailes y casas de sitas. El sexo oral, el sexo anal y el sexo vaginal. El oral es lo máximo y es el sexo fransés. Fransia es la madre de todo, de todo el visio y la perdisión.

Mucho más joven, Enrique F., me relataba en otra ocasión la historia de "la chaqueta [masturbación] a doble cachete" que les hizo a él y a George, una vieja que hacía autostop que subieron al automóvil. La imagen plástica, de ser "hermanos de leche", como una fantasía o suceso ansiado por el gusto libertino veracruzano, se concreta en que dos hombres mantengan relaciones sexuales con una mujer (ya sea coito o felación, el caso es que el semen de los varones entre en el cuerpo durante unas mismas 24 horas) durante el mismo día y de forma sucesiva. Esta circunstancia establece una suerte de "parentesco imaginario" que afianza las relaciones de confianza y camaradería entre ellos.

A una botella de licor y a una mujer, un varón se la puede "chiquitear": tomarla despacio, saboreándola y gozándola con calma y suavidad. Ante mi pregunta sobre la expresión de un compañero de mesa, "Vamos a chiquitearnos esta botellita", Raúl A. me contestaba que "Chiquitearla es tomarla despacito, suave, echándose uno su tiempo... Igual que cuando le metes el dedo a la vieja, en donde tu ya sabes, en la papaya, y en el chiquito [ano], y le andas despacito".

Analizar el mundo de las cantinas en Veracruz, supone adentrarnos en un mundo materializado y fantaseado, especialmente desde la óptica de los varones porteños. Enrique y su jefe solían acudir a una cantina llamada "El Rinconcito". Para ambos el "dedear" a las meseras, suponía una práctica deseable y vinculada al convivio y tomar trago entre varones en 
ese escenario. Así describía Enrique una escena de "dedeo", en esa misma cantina:

Estando chupando un viernes con mi jefe en "El Rinconcito", que me agarro a una mesera y que la dedeo, y luego saco el dedo y lo huelo, iQué aroma!, y que digo al maniático de mi jefe: "Jefe, huela el aroma". Y me contesta: "Esa vieja está caliente, huele muy bien”. ¡Y que iba a oler bien esa madre!,iii gúacala!!! [expresión de ascol!

La práctica/fantasía del "dedeo" a una mujer, aparece conectada con la idea de que a través del aroma del flujo vaginal femenino, el hombre dispone de unos indicios acerca del grado de excitación y "calentura" de la misma (según me comentaban Enrique y Constantino), y de la salud/enfermedad de esa persona. Así me describía George el "dedear" como una forma de prueba o "cata" de la "limpieza" de una mujer, antes de mantener relaciones sexuales con ella:

Un sabio doctor me dijo, cuando yo andaba trabajando en la Veterinaria, al verme que yo era muy desmadroso, que me cuidara de las viejas. Que el secreto, la prueba para saber si uno podía estar con una vieja era meterlas la mano hasta adentro, dedearlas bien y luego oler el aroma, oler esa madre. Si olían a limpio, como a aceite "Tres en uno" de engrasar, adelante con ellas, se podía uno comer esa papaya bien tranquilo, pero si olía como a marisco entonces ni madres, porque podía tener ahí una infección.

VI. Categorías morfológicas del gusto veracruzano (COMPOSTURA, GROSERÍA Y REVOLTURA)

Después de indagar en esta cultura urbana y la vida cotidiana veracruzana, he podido evidenciar una preocupación — si se quiere "barroca"-, por preservar y dramatizar las formas en cualquier interacción —social, sexual, gustativo-culinaria-. Al mismo tiempo es patente un tipo de aversión a descomponer la forma o la figura en todos los aspectos de la vida social, desde las relaciones de amistad en el convivio (conviviazgo), hasta las relaciones sexuales y "amorosas", o las de la comensalidad y la propia materialidad de las comidas o "platillos".

En Veracruz, las gentes tienen la convicción de que las comidas y las palabras pueden ser groseras, o convertirse en groseras por una falta de cuidado de las formas. Así las expresiones coloquiales alusivas al "chingar", las "mentadas de madre", aunque sean dichas en broma, son percibidas como groserías o "leperadas". Lo grosero es una categoría estética y del gusto relevante para los veracruzanos, y de la importancia de las groserías en las hablas e interacciones cotidianas, dan cuenta la infinidad de eufemismos 
utilizados con profusión ${ }^{30}$, que aluden a términos groseros, para el buen tono de la conversación.

El estereotipo del jarocho como grosero y lépero, elaborado por la cultura nacional mexicana, insiste en su alegría "desbordada", y la retórica periodística e institucional local sobre el carnaval, destaca que es este el momento festivo apropiado para "desbordarse". Ese "desborde" —un grado estético próximo al de la grosería-, implica una difuminación de los perfiles sociales habituales, una clase de descompostura - un descomponerse de las formas-. Es probable que el juego de encarnar lo grosero en algunas manifestaciones estéticas y sensoriales, tanto en platos de comidas como en actos corporales implicados en la comensalidad y la sociabilidad, pueda estar conectado con la necesidad de exorcizar el peso de "lo grosero", cargado sobre las espaldas de los jarochos por el estereotipo nacional.

En este punto, creo necesario hacer una reflexión sobre la morfología de los platillos y de las prácticas sexuales en el puerto de Veracruz. Los términos "grosero" e incluso "grosería" son aplicados en esta ciudad a algunos platos o tipos de comida, tanto de tipo tradicional - un "tacote" o taco enorme, una "torta cubana"-, como de tipo internacional y globalizado —un "sándwich" - , para expresar la abundancia y saturación de ingredientes heteróclitos en un mismo plato, pero sobre todo la ruptura del canon y perfil formal del plato, bien por haber aumentado su forma y tamaño de modo exagerado, bien porque se "deshizo" su forma hasta fundirse y confundirse los ingredientes de la comida. Entre otras, selecciono las siguientes expresiones de mis informantes en este sentido:

- Doña Mari, hablando de un sándwich que me preparó a la plancha para cenar decía: "Se hizo de manera grosera. Es una grosería de sandwich porque se fundió demasiado, se deshizo"(el queso se fundió demasiado con los otros ingredientes).

- Teresa V., hablándome de una cantina del mercado señalaba: "Aquí ponen unas tortas muy sabrosas, muy ricas, pero de lo grandes que son, de las cosas que le ponen, que se salen de la torta y todo, son hasta groseras. ¡A mí se me quita hasta el hambre solo de verlas!”.

Pero esta morfología moral y gustativa que apreciamos referida a algunos platillos que se consumen en Veracruz, también es aplicada en el discurso de los varones a las figuras, cuerpos y siluetas femeninas cuyas formas o perfiles originales también han aumentado de tamaño o se han

30 —_ ¡Ah su...!, ¡Ah su mecha!, ¡Pá su...!, ¡Pá la maquina!” por “¡Ah su madre!, ¡Pá su madre!, ¡Pá la madre!. O "¡Nos dio en la torre!, ¡En la torre, mi general! por "¡Nos dio en la madre", "En la madre". O "Valió queso" por "Valió verga" o "valió madres". 
descompuesto por el aumento de la grasa corporal. El término que se utiliza para describir a estas mujeres es el de "fodongas". En una entrevista con un octogenario don José O., éste me hablaba de cómo las mujeres "gordotas" del barrio le perseguían y querían mantener relaciones sexuales con él, pero que a él no le gustaba eso:

No me gustan las mujeres gordas...fodongas... aquí en el barrio a cada rato me vienen buscando, y me dicen que ¡venga!, que ¡vamos!, pero a mí no me gusta así cochino, a mí me gustan las mujeres jóvenes delgadas, esbeltas, con una cintura que se pueda agarrar con una mano, con la piel todavía tersa y suave, dulce, una mujer que le ilusione a uno, y así poder hacer la funsión.

Esta consideración, es compartida por varones veracruzanos más jóvenes de edad, como en una ocasión en que Romeo C., catalogaba a tres señoras de una mesa próxima en el Café de La Parroquia, como "viejas fodongas y hediondas". Se trataba de tres señoras de más de 50 años, de complexión gruesa, y de aspecto algo desaliñado, con vestidos de telas y cortes baratos o "nacos" (horteras), con unos cuerpos rellenos y cuyas telas comprimían los pliegues de grasa. Sus peinados eran algo descuidados y no parecían haber pasado por la estética/peluquería - como hacen usualmente las damas veracruzanas para ir a ese café- desde hacía bastante tiempo. En suma, los adjetivos "fodongas" y "hediondas" señalaban unas formas descompuestas, gruesas, y sobre todo "fuera de lugar" en uno de los espacios emblemáticos de la vida social —en especial de las clases medias- de la ciudad.

Por otra parte, lo cubano es concebido en la cultura e imaginación urbana veracruzana como paradigma de "la revoltura", de la fusión y difuminación (grosera) de los perfiles, en los discursos sobre la santería cubana y sus santeros, en las comidas cubanas, y en el trato personal y tendencia al exceso que se piensa como connatural de los cubanos. Esta "revoltura" y "grosería" - como lo expresan en sus comentarios mis informantes ante la sola contemplación de la posibilidad de comerse una-, se condensan en un "plato tradicional" veracruzano llamado "torta cubana". Así me explicaba de qué está compuesta, José Luis G., mientras era notorio su goce en la enumeración o el listado largo de ingredientes que llevaba:

Una torta cubana es una torta ¡cubana, que trae de todo, todo revuelto ahí! Lleva muchos ingredientes, lleva aguacate, lechuga, frijoles embarrados en el pan como si fuera mantequilla, con los frijoles refritos, frijol negro, milanesa, pierna, jamón, jitomate, cebolla, queso, mahonesa, mantequilla, chile, salsa bien picosa. Con una torta de esas ya queda uno satisfecho. Una torta cubana lleva absolutamente de todo.

Una informante de Veracruz, Doña Mari, ante una "torta cubana" servida apenas conteniendo sus componentes (a punto de chorrear por los la- 
dos y desparramarse por el plato), enunciaba sus sentimientos de hartazgo, incluso de asco, que le provocaba la contemplación de la misma: "es una grosería de torta", sintiéndola como si fuera un insulto a su persona, y a la etiqueta y reglas de comensalidad.

Otro plato "cubano", que ilustra la "revoltura" y condensación de la pluralidad, es el "pollo a la cubana", del que mi casera Doña Mari me explicaba su composición, antes de comerlo en su casa:

El pollo a la cubana, es un plato que aquí les gusta mucho. Lleva muchos ingredientes, y su sabor es dulce y salado a la vez, algo que no le gusta a todo el mundo, pero a nosotros sí. Lleva almendras, cacahuates, tomate rojo, chile, plátano roatán, no lleva azúcar, el plátano es lo que le da el sabor dulce...Ah si, lleva aceitunas, ajo, pimiento morrón, pasas, zanahoria...Se come acompañado de arroz colorado.

Si la torta "cubana" es un plato que se consume generalmente en un bar o cantina, y rodeado por otros varones del grupo de amigos, en algún momento del tránsito festivo-alcohólico de su convivio, el "pollo a la cubana" es una comida consumida en familia, en algún domingo o día señalado.

El exceso por acumulación de lo variado y exhuberancia de ingredientes, e incluso de los elementos gustativamente opuestos o plásticamente distantes (salado-dulce, mantequilla-frijol refrito untado, plátano roatán-pimiento morrón), pero también por la revoltura de los mismos en una sola entidad presentada de forma unitaria y discreta - ya sea un plato o un bocadillo-, una yuxtaposición leve o revuelto abrupto, son degustados (y pensados) en Veracruz como "cubanos", como cargados de atractivo para el paladar veracruzano, y cuya escasa diferencia — formal, identitaria- entre ambos haces de rasgos, se manufactura por la exageración o travestimiento pasajero de "lo propio" (lo veracruzano).

En la tarea de perfilar el ideal erótico y los motivos privilegiados en la imaginación sexual de los varones de Veracruz, también aparecen "las cubanas" como un mito sexual de gran vigencia y arraigo en la ciudad, unas figuras pensadas como encarnaciones de deseos y excesos sexuales diversos, pero que contrastan algo con el mito erótico, europeo y occidental, de la mulata cubana: en Veracruz "las cubanas" que encienden el gusto y pasión masculina no son las negras o mulatas, sino las "güeras cubanas", de piel clara y teñidas de rubio. Las cubanas en tanto que mito erótico y objeto sexual masculino, desvelan una fantasía erótica recurrente entre mis informantes (varones) veracruzanos, contenida en sus propias $-\mathrm{y}$ crudaspalabras: "Lo máximo para mí, es cotorrear [divertirme] con una cubana, culearme a una cubana".

De modo paralelo, Daniel N., comentaba que "el negro jarocho de aquí 
es muy cubano", lo que podemos tomar como una alusión al perfil "racial", al papel decisivo de la imagen del "negro" en la formación y vigencia del estereotipo del "jarocho" 31 . Una herencia identitaria cultural y estética "negra" (imaginaria en cierta medida), en la actualidad depositada en parte en la figura de los cubanos, y que es actualizada y dramatizada por los habitantes del Puerto mediante el recurso de "travestirse de cubanos" (presentarse con una identidad "a la cubana"). "Lo cubano", morfológica y moralmente, apela al exceso, a esa clase de mezcla saturada y contaminación que las gentes de Veracruz continúan experimentando como cercanas y atractivas (para sí y para los otros), y al mismo tiempo como peligrosas y fuente de contaminación. De este modo, la mezcla, la fusión más chocante e incluso "grosera", excesiva por su difuminación de perfiles y componentes, es presentada como la propia de una identidad en parte extranjera, pero también en parte interna, asumida como cercana y "fundida" para las gentes de Veracruz, como es la identidad cubana.

Me gustaría volver al pollo a la cubana, un plato con muchos y variados ingredientes, escenificando a su vez un mapamundi cultural (geográfico, gastronómico y de diferentes tradiciones) como el que escenifica la receta del mondongo a la veracruzana en las primeras páginas de este texto. ¿Qué hay de diferente en su receta, en su composición y en su valoración emotiva y gustativa, para que el pollo a la cubana sea considerado "revoltura", y el mondongo sea expresivo de la identidad y la tradición "veracruzana”? Quizás sólo la glosa "a la cubana".

\section{BOCADO (A MODO DE CONCLUSIÓN)}

Contrariamente a la vista y al oído, y en esto cercano al olfato, el gusto es un sentido de la diferenciación. La sensación gustativa remite a un significado: es al mismo tiempo un conocimiento y una afectividad que se encuentran en acción. Si la vista, el tacto o el oído a menudo permanecen indiferentes a lo que perciben, no ocurre lo mismo con el gusto, siempre comprometido con aquello que percibe. (Le Breton, 2007: 268).

Siendo el sentido del gusto el sentido de la diferenciación por excelencia, la exploración realizada permite iluminar los modos en que las retóricas veracruzanas que comprometen al gusto, alimenticias y sexuales, abordadas en estas páginas, bajo sus aparentes analogías y similitudes, resultan diferentes, conteniendo un distinto modo de proceder y exhibiendo una diferente lógica. Por un lado, las retóricas culinarias proceden por acumu-

31 Como demostró Ricardo Pérez Monfort en "Lo "negro" en la formación del estereotipo jarocho durante los siglos XIX y XX"(1996b). 
lación, por saturación de elementos, dentro de una lógica que podíamos denominar como de la enumeración y la yuxtaposición —con las figuras de la retórica de la enumeración (en ocasiones barroca) y la hipérbole, entre otras-. En cambio, las retóricas sexuales exhiben una lógica de selección, de particularización del gusto ante una oferta plural, manifestando una suerte de "lógica de ambigú" — en buena medida, con las metonimias (la parte por el todo: "culo" por "mujer"), como figuras retóricas recurrentes en este tipo de lógica y discurso- Ambas retóricas y lógicas, constituyen una parte del entramado de sentidos que dinamizan las vidas de los habitantes de esta cultura urbana veracruzana.

El veracruzano sería un gusto particularizado que tiende a ser exhibido narrativamente y en la acción social en contextos de goce o placer compuesto, y ante una oferta plural de "bocados" (gastronómicos, sexuales) como en un ambigú. El elemento diferenciador, la singularidad de este gusto veracruzano que hemos revisado —su "ensamblaje", de "coupage" cultural—, en buena medida provocado y conformado por las percepciones y apreciaciones centradas en comidas y cuerpos, atractivos y estimulantes - $\mathrm{O}$ repelentes y disfóricos - se encuentra probablemente en su marcada oralidad, en un fuerte anclaje en lo sensorial, y en una marcada hiperrepresentación en las conversaciones y prácticas sociales de la vida cotidiana citadina, en una peculiar combinatoria de morfología cultural —estética y moral- de raigambre caribeña. He tratado de evidenciar la tendencia en la imaginación veracruzana a poner "en circulación" social, difundir ante los demás, propios y extraños, esas historias — en ocasiones verdaderos ejemplos de microrrelatos-, comentarios y calificaciones sobre platos apetitosos —en su conjunto, y en la enumeración de sus ingredientes-, y sobre cuerpos gustosos — de modo integral, y en la focalización e inclusive fetichización de ciertas partes o miembros-. Todo ello tiende a manifestarse de modo profuso y ubicuo en los discursos públicos de la ciudad — con mayor intensidad en conversaciones y por boca de los varones-.

\section{BiBliografíA CITADA}

Ackerman, D. 2006. Una historia natural de los sentidos. Barcelona: Anagrama.

Andrade, O.1928. "Manifiesto Antropófago", Revista de Antropofagia, Año I, n.․ 1.

Bachelard, G.1982. "El mito de la digestión”, La formación del espíritu científico: 199214, México: Siglo XXI.

Bajtin, M. 1987. La cultura popular en la Edad Media y en el Renacimiento, Madrid: Alianza.

Barthes, R. 1977. Sade, Loyola, Fourier. Caracas: Monte Ávila Editores.

Barthes, R. 1987. "Lectura de Brillat-Savarin", en R. Barthes, El susurro del lenguaje. Barcelona: Paidós. 
Benítez, F. 1992 [1948]. "La ruta de Hernán Cortés", en M. Poblet Miranda (ed.), Cien viajeros en Veracruz. Crónicas y relatos, t. XI: 201-207, México: Gobierno del Estado de Veracruz.

Benítez Rojo, A.1998. La isla que se repite. Barcelona: Casiopea.

Bourdieu, Pierre, 1988. La distinción. Criterios y bases sociales del gusto. Madrid: Taurus. Brillat-Savarin, J. A. 1986 [1825]. Fisiología del gusto. Barcelona: Bruguera.

Châtelet, N. 1985: La aventura de comer. Madrid: Júcar.

Classen, C. 1993. World of Sense: Exploring the Senses in History and Across Cultures. Londres y Nueva York: Routledge.

Classen, C. 1997. "Fundamentos de una antropología de los sentidos". Revista Internacional de Ciencias Sociales 153: 401-412.

Falk, P. 1991. "Homo culinarius: Howard an historical anthropology of taste", Social Science Information 30 (4): 757-790.

Flores Martos, J. A. 1996. "Una mitología urbana: las historias de 'locos' y 'personajes' en Veracruz", La Palabra y el Hombre 99: 133-148.

Flores Martos, J. A. 2002. "Cuatro piezas barrocas veracruzanas y una fantasía postcolonial", Cuadernos Hispanoamericanos 621: 37-52.

Flores Martos, J. A. 2004. Portales de múcara. Una etnografía del puerto de Veracruz. Xalapa: Editorial de la Universidad Veracruzana.

Flores Martos, J. A. 2005. "Hacia una teoría cultural del trauma y la violencia cotidianas en el Puerto de Veracruz", Nueva Antropología 65: 93-112.

Fourier, C. 1973. La armonía pasional del nuevo mundo. Madrid: Taurus.

García Alonso, M., A. Martínez, P. Pitarch, P. Ranera y J. A. Flores Martos (eds.). 1996. Antropologia de los Sentidos. La Vista. Madrid: Celeste Ediciones.

García de León, A. 1992. "El Caribe Afroandaluz: permanencias de una civilización popular", La Jornada Semanal 12-01-1992: 27-33.

Gerbi, A. 1982. La Disputa del Nuevo Mundo. Historia de una polémica 1750-1900. México: Fondo de Cultura Económica.

Goody, J. 1995. Cocina, cuisine y clase: estudios de sociología comparada. Barcelona: Gedisa.

Goody, J. 2002. "The Anthropology of the Senses and Sensations", La Ricerca Folklorica, (April 2002, Antropologia delle sensazioni) 45: 17-28.

Hénaff, M. 1980. Sade. La invención del cuerpo libertino. Barcelona: Destino.

Holtzman, J. D. 2006. "Food and Memory", Annual Review of Anthropology 34: 361-376.

Howes, D. (comp.). 1991. The Varieties of Sensory Experience: A Sourcebook in the Anthropology of the Senses. Toronto: University of Toronto Press.

Howes, D. 2003. Sensual relations: engaging the senses in culture and social theory, Ann Arbor: The University of Michigan Press.

Howes, D. 2004. Empire of the Senses: The Sensual Culture Reader. Oxford: Berg.

Huerta Calvo, J, 1989. "Lo carnavalesco en la teoría literaria de Mijail Bajtin", en J. Huerta Calvo (ed.). Formas carnavalescas en el arte y la literatura. 13-31, Barcelona: Ediciones del Serbal.

Kant, I.1999 [1790]. "“Crítica del juicio" seguida de las observaciones sobre el asentimiento de lo bello y lo sublime", Alicante: Biblioteca Virtual Cervantes, http: //www.cervantes virtual.com/FichaObra.html?Ref $=2543$

Korsmeyer, C. 2002. Making Sense of Taste. Food and Philosophy. Ithaca: Cornell University Press. 
Korsmeyer, C. (ed.). 2005. The Taste Culture Reader: the Experience of Food and Drink. Oxford: Berg.

Lalonde, M.P. 1992. "Deciphering a meal again, or the anthropology of taste", Social Science Information 31 (1): 67-86.

Le Breton, D. 2007. El sabor del mundo. Una antropología de los sentidos. Buenos Aires: Nueva Visión.

Lezama Lima, J. 1993. La expresión americana. La Habana: Ed. Letras Cubanas.

Lezama Lima, J. 1994. Diarios. México: Era.

Lévi-Strauss, C. 1981. Mitológicas III. El origen de las maneras de mesa. México: Siglo XXI.

Litvak, L.1986. El sendero del tigre. Exotismos en la literatura española de finales del siglo XIX, 1880-1913. Madrid: Taurus.

Ontañón, E. 1992 [1946]. "Manual de México", en M. Poblet Miranda (ed.), Cien viajeros en Veracruz. Crónicas y relatos. t. IX: 239-243, Xalapa: Gobierno del Estado de Veracruz.

Pérez Monfort, R. 1996a. "Expresión y colorido de la cultura popular en el Puerto de Veracruz, siglos XIX y XX", en A. Antuñano Maurer et al., Veracruz, primer puerto del continente. México: ICA/Fundación Miguel Alemán.

Pérez Monfort, R. 1996b. "Lo "negro" en la formación del estereotipo jarocho durante los siglos xIX y xx", Foro Académico del III Festival Internacional Afrocaribeño, Veracruz (m.s).

Pitarch, P. 1995. "Un lugar difícil: Estereotipos étnicos y juegos de poder en los Altos de Chiapas", en J.P. Viqueira y M. H. Ruz (coords.), Chiapas: los rumbos de otra bistoria. 237-250, México: UNAM.

Pitol, S. 1996. El Arte de la Fuga. México: Era.

Quinto Rivera, Á. 1990. “Cultura!: en el Caribe nuestra consigna. Obsesivas variaciones sobre 'La cimarronería como herencia y utopía', Identidad cultural y modernidad. Nuevos modelos de relaciones culturales. Barcelona: Federació Catalana D' Asociacions i Clubs UNESCO.

Ramos, L. A. 1983. Intramuros. Xalapa: Editorial de la Universidad Veracruzana.

Rejano, J. 1992 [1944]. "La esfinge mestiza", en M. Poblet Miranda, Cien viajeros en Veracruz. Crónicas y relatos. t. IX: 199-210, Xalapa: Gobierno del Estado de Veracruz.

Stoller, P. 1989. The Taste of Ethnographic Things: The Senses in Anthropology. Philadelphia: University of Pennsylvania Press.

Stoller, P. 1997. Sensuous Scholarship. Philadelphia: University of Pennsylvania Press.

VV.AA., 2005. Diccionario Panhispánico de Dudas. Madrid: Real Academia Española de la Lengua.

Fecha de recepción: 17 de noviembre de 2008

Fecha de aceptación: 19 de febrero de 2009 